\section{BIRTH OF A SCIENCE}

\section{Franklin and Newton}

An Inquiry into Speculative Newtonian Experimental Science and Franklin's Work in Electricity as an Example Thereof. By Bornard I. Cohen. (Memoirs of the American Philosophical Society, Vol. 43.) Pp. xxvi+657. (Harvard University Press: Cambridge, Mass.; Oxford University Press: London, 1968.) 57s.

A complete study of the progress of physics in the eighteenth century (a study still unwritten!) would recognize that it presents two equally important aspects, the origin of which could be traced to the previous century: on the one hand, a profound transformation of the social background of scientific activity; on the other, the development of new methods of investigation and analysis of the physical phenomena, of a new attitude of mind, marked by tho overwhelming influence of Newton's thought and discoveries. In his masterly analysis of Benjamin Franklin's scientific work, Professor Cohen has deliberately confined himself to the last-named aspect, emphasizing the "Newtonian" character of Franklin's activity-in spite of the splendid opportunity his hero would have offered him of illustrating just as forcefully the former aspect.

Indeed, Franklin himself, as well as all the other physicists who were in relation with him, and whose contributions aro minutely discussed in the book, were representatives of the new type of scientist that occupied in the course of the century the scene left vacant by the extinction of the old seats of medieval learning. Except for some flickering at Cambridge, the tradition of scientific education and research passed from the ancient universities to more progressive ones in Scotland, Holland, Germany and Sweden, or to institutions of a novel form, the academies and scientific societies; but besides this academic support, scientific progress received a decisive impact from those self-educated men belonging to the domain of trade and industry or the liberal professions, of which Franklin is one of the greatest. Of the conditions of scientifie research, the means of diffusion of knowledge and communication among the scientists, the coordinating and sanctioning role of the scientific societies, the reader gets no explicit hint, but is left to form for himself a picture of these circumstances from occasional details of the author's minute account of the succession of events. The whole organization of the book is so firmly focused on the purely internal logic of the development of scientific ideas as to give the impression that it happens on an Olympian scene.

Within this solf-imposed limitation, however, Cohen has drawn a picture of the birth and growth of the science of electricity so admirable in every detail that it is not too much to call it definitive. Cleverly built up around the two dominating personalities of Newton and Franklin, his analysis throws full light upon the elaboration of the essential ideas on the nature of electricity in close interaction with the cxperimental investigation of the phenomena, and traces the origin of this fruitful method to Newton's Optics. In this connexion, he gives a discussion of the way in which Newton conceived and used "hypotheses" which but for a minor flaw would sottle this vexed question completely; my only reservation concerns the author's allusion to Newton's repeated attempts at explaining gravitation by some interaction between matter and ether: he mentions them as if they were all based on the same hypothetical mechanism, whereas they are in fact quite different, and dramatically illus. trate Newton's hesitations and persistent dissatisfaction with this problem. Apart from this, the essential difference of mothod between the Principia and the Opticsthe two pillars upon which Newton edified his new natural philosophy-is very clearly brought out and shown to persist throughout the eighteenth century in the parallel development of astronomy and geodesy on the one hand and experimental physics on the other.

The present edition of Cohen's work is an identical re-issue of the original publication, ten years ago, by the American Philosophical Society. It will thus become more easily available to the historians of science, for whom it is indispensable; but one must hope that it will also find the wide diffusion it deserves outside this circle of specialists, and especially among the young generation of science students.

L. Rosenteid

\section{SPECIALIST PHYSICS}

\section{The Theory of Neutron Resonance Reactions}

By J. E. Lynn. Pp. xiii + 504. (Clarendon Press: Oxford; Oxford University Press: London, 1968.) $100 s$.

Twenty years ago a monograph of this bulk, in this long-established and prestigious "International Series", would probably have encompassed most of nuclear physics; ten years ago such a work might have been devoted to, say, the whole of nuclear reactions. Today's monograph zooms in and shows us more and more of less and less: five hundred pages, replete with innumerable charts, tabulations and some six hundred references all devoted to the theory of one type of nuclear process-resonance interaction of low-energy neutrons with individual atomic nuclei. Scientifically this is, of course, only a specialized part of the general subject of nuclear reactions, and singling it out for treatment as subject sui generis might be considered rather artificial. On the other hand, the great significance of these neutron phenomena in what is, today, a vast technology, and the existence of a correspondingly vast accumulation of empirical information, may well justify devoting to this subject the detailed and thorough treatment it receives.

Tho work comprises both a full survey of the facts (although not an exhaustive one, the author affirms), and an exposition of their theoretical interpretation in torms of basic quantum-mechanical principles and nuclcar phenomenology. Topies treated are: formal theory of nuclear reactions, level spacings and their statistical distribution, neutron elastic scattering and radiative capture, and neutron induced fission. The theoretical treatment is sophisticated and authoritative; and although detailed and comprehensive, a reader not already familiar with the theory of nuclear reactions will not find it easy to follow. Lucidity is often obscured by the mass of detail and complexity: at times the physical principles involved. are more clearly expounded in the original papers and review articles to which reference is made. The author appears to have special difficulty in deciding how much or little background knowledge to attribute to his readers. At times, simple, even trivial, matters are excessively elaborated; at others, the demands made on the reader are very substantial. This erraticism is perhaps the main obstacle to clarity.

Despite the occasional slips, and the absence of figure captions here and there, the production, as one expects of the Clarendon Press, is of a high standard. Those, however, who possess earlier works in the series may be excused a nostalgic sigh for the days when the printing was on really opaque paper!

A work of this sort by an authority in the field could clearly fill the role of a standard work of reference. If it is to do so it deserves a far, far better subject index, as well as a proper reference list of definitions of symbols used. Who expects to find (next to "Nuclear explosion"!) an isolated entry " $\mathrm{Nu}$ ", especially when the only other symbol so honoured in the index is "Alpha, see ratio of capture to fission"!

All in all, this is a book for specialists by a specialist, vintage 1968 .
S. DEvons 